\title{
Transforming Temporary Organizations To Permanence: Examining The Role Of Information Systems
}

\author{
Gaurav Gupta \\ Indian Institute of Management \\ Calcutta \\ gauravg13@,iimcal.ac.in
}

\author{
Prof. Indranil Bose \\ Indian Institute of Management \\ Calcutta \\ bose@,iimcal.ac.in
}

\begin{abstract}
Temporary organizations might not remain such in perpetuity. They may transform into permanent form over time. Information systems are pivotal to such transformation. In this study, we examine such transformation using an exploratory case study of a firm operating in the domain of disaster management. We examine the changing role of information systems in driving such transformation. In this regard, we propose a dynamic framework for examining these dynamics across different phases of this transformation. This study concludes that information systems hold significant influence on communication, coordination, and control of various teams in such temporary organizations. When implemented appropriately, it reflects variedly at different stages of such organizational transformation. This study helps develop a vocabulary for future research on the theme of transformation for such organizations.
\end{abstract}

\section{Introduction}

The field of temporary organizing in the form of projects or temporary organizations has gained prominence in last two decades [21]. Researchers have primarily focused on the organizing of temporary projects within permanent firms characterized by eternal existence [15]. The context of temporary organizations has received little attention. Such temporary organizations are formed around specific activities like movie making [11] and software development projects [16].

Temporariness has primarily been studied from a static perspective in literature. Organizations which were once temporary or project-based can transform into permanent organizations with time. Muller-Seitz and Sydow [26] discussed the process of this transformation using the case study of SEMATECH which was started as a temporary system by semiconductor manufacturers was turned into a permanent system as a result of persistence across various triggering events and self-reinforcing processes. However, academic scholarship on the role of enabling mechanisms for such transition is lacking. With the exponential increase of information useful for managing such disconnected projects, it has become increasingly important to explore the role of information systems (IS) in developing such transformation processes.

We have attempted to examine the mechanism of such transformation with a focus on the IS governing it. We aim to boost the discussion in this domain by engaging with a case study of an entrepreneurial firm named Doctors For You (DFY). It is a humanitarian organization which started in 2007 with the sole aim of serving the malaria victims in Mumbai by organizing various platelet drives through the help of medical student volunteers. However, over multiple renewals across different disaster relief projects, it transformed into a permanent firm.

Disaster management was interpreted as relief work (post-event) till the early 1990s, especially in developing countries like India. Tufekci and Wallace [28] categorize emergency response to disasters into pre-event and post-event response stages. An effective disaster management plan should integrate both of these stages within its objectives. Although, losses (as $\%$ of GDP) due to the impact of natural disasters are 20 times higher in developing countries than others ${ }^{1}$, there was hardly any importance given to the prevention of disasters regarding minimizing its potential impact or bringing about an institutionalized approach in planning disaster management. DFY realized that lack of trained medical personnel is one of the greatest bottlenecks in providing relief after disasters. There is an enormous amount of time that is wasted in identifying and mobilizing a team of such professionals to disaster-affected regions. This case study follows the

\footnotetext{
1 Topics 2000, Natural catastrophes - the current position, Special Millennium Issue, Munich Re Group, 1999, p. 14.
} 
evolution of DFY from a temporary organization of medical student volunteers to a permanent organization with continuing existence to provide services during both crisis and non-crisis situations. While doing so, we also help build a vocabulary to examine the transformation of such temporary firms into permanence. This study illuminates the dynamism in the roles of IS involved in the transformation of this organizational form.

\section{Theoretical background}

Temporary organizations represent an important form of organizational structures. They are described as aggregates of individuals temporarily collaborating for a shared cause [14, 27]. Lundin and Söderholm [21] made an early attempt at theorizing them by four characteristics, i.e., time, task, team, and transition. Although time was the most understood term in this context as it was what added "temporariness" to their character, it does not imply that they have a short duration [22]. Rather it refers to the collective awareness of its impending termination [23]. Task signifies the goals of the organization and is actionoriented. Uniqueness or repetitiveness of the task determines the type of temporary organization. Teams for temporary organizations are different from permanent ones as their aggregation is pre-determined to be governed by time. The significance of team in this context is regarding its relationship with the external environment in which the organization operates. Transition, on the other hand, refers to the causality associated with progression or accomplishment of a pre-determined objective before the termination of the organization. The idea of permanence in organizational theory is deeply rooted in the eternal character of the firm. Compared to temporary organizations, Lundin and Soderholm [21:439] describe them as being "more naturally defined by goals (rather than task), survival (rather than time), working organization (rather than team) and production processes and continual development (rather than transition)."

Temporary organizations have also been conceptualized as transitory units in permanent organizations [17]. In this view, they are treated as time-limited projects [29] executed by members of the permanent organization who are assembled around a particular task and this association terminates with the fulfillment of the project objectives. In temporary organizational forms research, the focus has mostly been on project-based organization i.e. an organization in which the project is the most important unit for production organization [5], or on project-based industries such as the production of films in the motion picture industry [2], in which the primary mode of operation is project based. Cova and Salle [7] challenge this terminal nature of the impact of projects on business but rather emphasize the process of linking project work with a strategic, long-term approach. There is a recognized need to illustrate the limitations of isolation of the theory of temporary organizations around time-restricted projects. There has been very little work to examine this transition of temporariness in permanent organizations. While there has been some work in trying to understand the circumstances and mechanisms that drive temporary organizations to become permanent [26], the focus has been on the initial conditions driving this transition. Further, the attention is on the permanent external environment affecting this change. The role of enabling systems especially in information-intensive environments driving this shift has found little mention in literature.

Traditionally, projects were considered to be agencies of larger organizations with some specific objectives [29]. Even in this form, the need for establishing information channels by the principal organization for communication and coordination has been realized. The role of IS in this vision was to monitor delivery of the project and its alignment with the outcomes. However, later scholarship, recognizing project-based organizations independently of such larger organizations has gained relevance primarily due to the growth of IS. Scholars as early as Galbraith [12] argued for the importance of investment in information systems for organizational design, the same principles followed for the design of permanent organizational forms from temporary projects. In such systems, the role of linking these diverse teams was entrusted with the manager but IS plays a pivotal role in establishing such linkages in modern information-intensive business environments.

In dynamic environments characterized by taskbased projects such as disaster relief, it is of particular importance to examine the changing role of IS in the transformation of a temporary organization into permanence. Disaster management consists of various activities like disaster mitigation, prevention, preparedness, response, evacuation, relief, and rehabilitation. All of these activities are project-based and primarily temporary in nature (except activities like disaster preparedness). Disaster management operations are information intensive activities [4] due to the high uncertainty [1] and complex information needs [3] of many stakeholders simultaneously [6]. Timely and accurate processing of crisis information and effective communication are critical elements of disaster relief operations [20]. The introduction of information technology-based tools during such situations present novel opportunities for 
entrepreneurship. Mobile platforms are especially useful in such situations primarily due to their portability and ubiquity [32]. Apart from the intended uses of mobile devices, they are capable of improvised, repurposive use [24]. Mobile apps offer additional functionality that goes well beyond the original communicative purposes of the device. WhatsApp is one such app which has been increasingly adopted to different business roles. The flexibility of this and other similar communication tools in different use cases has led to it being a proxy for information systems [8]. Yates and Paquette [30] discuss the role of social media technologies in the realization of a comprehensive approach through knowledge contributions by multiple stakeholders connected on a common platform. However, still, there has been a distinct lack of literature on the distinct mechanisms of their adoption in disaster management. Further, there is a need to examine the role of IS in alleviating the needs of the victims and serving them in such temporary emergency projects.

\section{Research methodology}

The research herein involves an exploratory qualitative case study [31], a method sensitive enough to capture and identify the theoretical underpinnings of a longitudinal phenomenon. In this study, the choice of a qualitative approach was based on the realization of the complexity of the process of transformation of an organizational form and the corresponding change in the role of S. This approach does not aim at providing irrefutable truth but at understanding the dynamics underlying a phenomenon [25]. Since it is hard to assign particular outcomes to the various changes that happened over time, qualitative case study methodology was chosen for this study. This case study was deliberately chosen due to the exemplary nature of this longitudinal phenomenon and long-term access to the firm's information. The case study approach allowed us to examine the changing role of IS in the process of transformation of the firm across different projects, their renewal, and formalization.

Table 1: Interviews conducted

\begin{tabular}{llc}
\hline Name & Role/organization & $\begin{array}{l}\text { Duration } \\
\text { (mins) }\end{array}$ \\
\hline $\begin{array}{l}\text { Dr. Ravikant } \\
\text { Singh }\end{array}$ & $\begin{array}{l}\text { Founder/entrepreneur, } \\
\text { DFY }\end{array}$ & 230 \\
$\begin{array}{l}\text { Dr. Anurag } \\
\text { Mishra }\end{array}$ & Joint Secretary, DFY & 50 \\
Dr. Mridul & Program Manager, & 47 \\
Kumar Deka & DFY &
\end{tabular}

$\begin{array}{lll}\text { Sunny } & \text { Project Coordinator, } & 40 \\ \text { Borgohain } & \text { DFY } & \\ \text { Sudhir } & \text { Chief Adviser, N.M. } & 20 \\ \text { Sudhal } & \text { Budhrani Trust } & \\ \text { Sarbjit Singh } & \begin{array}{l}\text { Emergency } \\ \text { Specialist, UNICEF }\end{array} & 20 \\ \text { Sahota } & \begin{array}{l}\text { India } \\ \end{array}\end{array}$

A case study is an empirical investigation of a contemporary phenomenon within its actual context, which means that the boundaries demarcating phenomenon and context are still blurred, and several sources of evidence need to be used [31]. Hence, our data collection process focused on detailed, in-depth, semi-structured interviews [9], supplemented by analysis of various reports and documents. This triangulation of interview transcript data with documentary analysis helped confirm or refute the information collected from the interviews [18]. The unit of observation for this study was the founder of the firm, program manager, various project managers, investors of different charities and managers from external partners (like UNICEF) who witnessed the transformation of DFY from a project-based temporary organization to a permanent form (see details in Table 1). These actors were assumed to have seen and played a key role during this metamorphosis, and they were chosen based on their information potential [19]. Interviews were conducted at two instances, i.e., 2014 and 2016 with an average duration of 40-50 minutes. This choice of conducting the interview twice was an attempt at enhancing the internal validity and reliability of the data over time. The next step involved writing up condensed descriptions of how DFY evolved from being a temporary system to becoming a permanent, perpetual organization, and this content was analyzed with reports and other information gathered from the company's website. Based on the suggestions by Eisenhardt [9] and George and Bennett [13] for analysis of qualitative data, the study captures theoretically grounded and relevant insights which are sustained over time within the context of this research.

\section{Case discussion}

DFY is a humanitarian organization formed by doctors, medical students, and other like-minded people. The thrust of DFY's work is to provide medical relief, sustainable healthcare services, capacity building and risk reduction activities in crisis and noncrisis situations. Since its inception in 2007, the organization has been working extensively with vulnerable communities in six states of India providing efficient, effective and equitable distribution of health 
care for all. Presently, it has more than 500 members and 1000 registered volunteers assigned to it who are always ready to support in disaster situations.

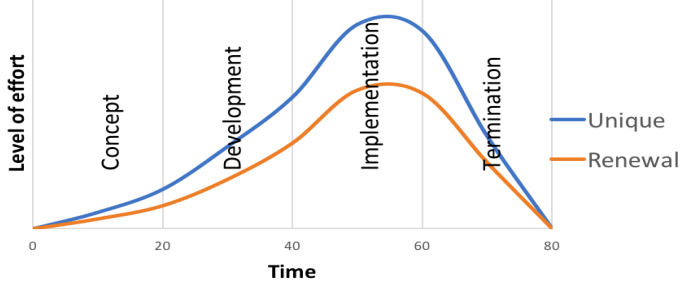

Fig. 1: Stages of a project's lifecycle

When Mumbai witnessed one of the worst outbreaks of malaria and dengue, DFY was envisioned to provide medical relief to the affected. It was conceptualized as a unique project to help with disaster relief for a single instance. It hence followed the four stages of unique projects as proposed by Lundin and Söderholm [21], linearly. The founder identified the need for temporary medical volunteers and conceptualized a set of proposed medical relief services accordingly. He further developed his idea with support from his colleagues and teamed up with the Think Foundation to launch the Lifesavers Club, and organized a first-of-its-kind platelet donation drive. Each donor was given a bar-coded donor card that had information such as their name, age, date of birth, blood group and the last recorded donation by the cardholder. This project implementation enabled the best use of the platelet aphaeresis machine which was critical for this drive. This implementation was so successful that the number of platelet donors at KEM hospital in Mumbai alone doubled in just 45 days and thousands of lives were saved. The team later organized several such drives across the city, but the knowledge gained from the first activity helped reduce subsequent effort. This project was subsequently gracefully terminated after fulfilling its initial objectives (see Fig. 1). Like unique temporary organizations, it was created for a single, specific situation which was not expected to occur again [21].

However, again in 2008, during the Bihar floods, it was felt that there was no dedicated medical disaster response team in India for the disaster relief work. Armed with infrastructural support from the Indian Railways and in association with other NGOs such as Youth for Equality and Mercy Malaysia, DFY launched a massive medical relief \& rehabilitation operation. Armed with the learnings from the last project, the organization was again renewed for medical relief and rehabilitation operations. A team of 45 doctors was immediately formed and sent for relief work. The team worked in Bihar for six months treating over 130,000 patients especially women and children. Such instances started repeating, and the organization began behaving like repetitive temporary organizations (see Table 2 below).

\section{Table 2: Repetitive temporary organization characteristics (adapted from Lundin \& Söderholm, 1995)}

\begin{tabular}{|c|c|c|}
\hline Criteria & Repetitive tasks & $\begin{array}{l}\text { DFY } \\
\text { characteristics }\end{array}$ \\
\hline Goals & $\begin{array}{l}\text { Immediate, } \\
\text { specified }\end{array}$ & Disaster specific \\
\hline Experience & $\begin{array}{l}\text { Own or codified } \\
\text { by professionals }\end{array}$ & $\begin{array}{l}\text { Trained medical } \\
\text { professionals }\end{array}$ \\
\hline Competence & $\begin{array}{l}\text { In codes and } \\
\text { tacit knowledge }\end{array}$ & $\begin{array}{l}\text { Prior experience } \\
\text { in other disaster } \\
\text { relief operations }\end{array}$ \\
\hline $\begin{array}{l}\text { Leadership of } \\
\text { temporary } \\
\text { organization }\end{array}$ & $\begin{array}{l}\text { Low or middle } \\
\text { managers }\end{array}$ & $\begin{array}{l}\text { Dr. Ravikant } \\
\text { (founder) }\end{array}$ \\
\hline $\begin{array}{l}\text { Development } \\
\text { process }\end{array}$ & Reversible & Linear \\
\hline Evaluation & Result oriented & $\begin{array}{l}\text { Definitive } \\
\text { criteria like } \\
\text { number of } \\
\text { patients treated } \\
\text { Experiential }\end{array}$ \\
\hline Learning & Refinement & $\begin{array}{l}\text { knowledge } \\
\text { assimilation }\end{array}$ \\
\hline
\end{tabular}

After each successful project, the operations of the organization started getting standardized through experiential knowledge accumulation. A large part of the team was created specifically for each project with local volunteers, but a few core members with experience of earlier projects helped reduce efforts needed for initiation of each such project instance (Fig. 1). Further, such frequent renewals led to a temporal overlap of these different relief projects. One project would continue even after initiation of a new one and hence the various teams and their tasks started overlapping too. However, since the organization was designed around project-based tasks, it retained the time, task, team and transition specific characteristics of temporary organizations [21]. The emergence of a temporary entrepreneurial organization into a permanent form is characterized by high complexity owing to the need for repeated alignment of project and team objectives in distinct operating conditions unique to each project task. The core function of the internal information system needs to be channelized to specific targets to achieve desired outcomes for the whole team. To understand this process better, we explore this transformation in the following stages, i.e., instantiation, renewal, and institutionalization, based on the priority of the organizational characteristics and 
the corresponding role of the dominant information system. DFY started as a temporary organization with the clearly defined objective of providing medical relief after any disaster, but it was able to transform the nature of the organization to permanence over these multiple phases. The activities across these stages might overlap under different contexts, but the antecedents and outcomes for each stage retain its uniqueness. These phases represent a conceptual segregation of the priorities of the various organization characteristics (i.e., time, task, team, and transition) and corresponding effort needed for this transformation into permanence.

\subsection{Project Instantiation}

As discussed earlier, DFY was started with the sole purpose of providing medical relief to the victims of the malaria outbreak in Mumbai. However, the task of providing relief could not have been fulfilled alone by him. He identified the specific needs of the malaria victims in Mumbai and then designed his operating model accordingly. He identified a team with the requisite skills from his professional network and further channelized his passion through them even to the ground level volunteers. However, owing to the newness of the initiative, the team had limited knowledge of the tasks and procedures. The structure of the tasks was not clearly defined, and the team members had to create solutions for each complication themselves. Since the resources were limited, the team had clearly defined temporal bounds for providing their services. Further since the expected outcomes of the project were clearly defined, the transition was structured and attainable. This being the first instance of the project instantiation, the efforts needed for all of the different criteria defining a temporary organization (like the task, team, time and transition characteristics) was similar, owing to congruent priorities.

As mentioned earlier, all the tasks and activities like identification of the problem, assessment of internal capabilities, recruitment of an appropriately skilled team and implementation and improvisation, were unique and their corresponding solutions unfamiliar. During this phase, communication between the team members and the central team was critical. Owing to the inexperience of the team to resolve various issues faced by them to provide medical relief to the affected, communication became an important aspect of their service. Since conventional communication systems were usually disrupted in such situations, the team depended on satellite phones and messengers to communicate with the base center. It also helped the team to conduct its activities effectively.

\subsection{Project Renewal}

Armed with the success and experience of the last project, DFY assessed its capabilities for providing such efforts again in the future. It identified the various challenges faced by the team in the form of administrative and regulatory challenges which hampered their overall efforts. While doing so, it also realized the need for persistent efforts in this domain to cause measurable transition for such relief situations. In 2008, during the Bihar floods, the team revisited its learnings to create a team swiftly and dispatched them to the disaster region swiftly. This time too they faced various issues related to administrative procedures for setting up relief camp and providing volunteer services armed with their experience from earlier projects, they responded to it more effectively in this instance. They partnered with various other local bodies with significant influence on the local administrative network to help them initialize their project immediately. The role of local volunteers in helping develop this initiative was significant. Lack of infrastructure, especially roads, forced these volunteers to walk often for miles with all the relief materials and other medical equipment. The results of such efforts would have been hindered by the lack of suitable supporting systems.

Knowledge accumulation from the previous project can only be utilized effectively if the nature of the task for renewal project is similar to the earlier instances. The teams started using messengers like WhatsApp to coordinate with the base center. This helped them tap past experiences from earlier project instances and establish a definite trajectory to the efforts of the various team members. The lack of formal channels for knowledge transference necessitated the need for renewal of this project with members of the earlier team having both the necessary medical skills and relevant project experience. However, their experience from the last project helped them realize the relative insignificance of defining strict temporal boundaries due to the high levels of uncertainty and complexity associated with relief work [1, 3]. However, the expected transition of the disaster situation is determined before the project instantiation, with clear and well-defined outcomes. The success in implementation of this project also highlighted the change in nature of the task characteristics from unique to repetitive form which is associated with a reduction in the efforts needed in all the stages of a project's life (see Fig. 1). After their successful efforts in alleviating the state of the victims of Bihar floods, the team renewed their medical relief projects for multiple similar disasters but the team, and the overall organization remained unstructured until 2010. It 
operated as a group of individual volunteers organized around specific disaster relief projects with challenges of lean period resource utilization, maximizing utilization of the experienced doctors and also mitigating operational issues like variable fund flow, lack of managerial skills among the members, etc.

\subsection{Institutionalization of the project organization}

Due to the issues encountered in the previous phase, DFY started structuration and refinement of its operations. It required identification of clear organizational objectives and tasks. Hence, it laid out its core mission as "To provide medical relief, sustainable health care services, capacity building, and risk reduction activities for vulnerable communities in both crisis and non-crisis situations", and hence the organization's activities became focused around this guiding statement.

Simultaneously, they also started formalization of the structure of the organization around a Core + Flex operating model. In this organizational structure, the key members of the organization and the doctors with management background form the core group. There were eight permanent doctors in the DFY core group in its various regional offices. The core group can rebuild this organization if at an adverse time a ramp down is required. The flex (flexible part) team is built based on rescue operations and project-based needs. The local doctors and volunteers are preferred in this group for capitalizing on the local knowledge and for minimizing the risk of attrition due to resource reallocation. Each project team is built with an even mix of medico and non-medicos. Though demand of medicos is very high in events of disaster, there are many tasks which a trained non-medico can perform with the guidance of a medico. This way the capacity to reach people and provide medical assistance improved manifold. However, the lack of experience in such scenarios was especially challenging for such teams. Therein access to WhatsApp groups in which regional center supervisors monitored and controlled the team activities, played as a boon for them. Although these groups were created immediately after DFY identified a relief project to provide their services, they continued to grow after the initial operations. There were clearly defined hierarchies and roles even within such groups and hence were early signs of the perpetuity of the organizational form.

Further, the core areas of intervention for them shifted from a primarily relief model to a sustained capacity building and preparedness model. This also highlighted their conscious transformation from a temporary organization with predetermined life to an organization with eternal existence. Hence, time as a characteristic of the temporary organization was no longer significant. However, the transition of state (i.e., effect on the overall medical relief efforts) during each project was still determinate and hence significant in identifying the organizational characteristics for the transformation.

With institutionalization at the center of its efforts for perpetuity, it realized the need for continuous communication with doctors, non-medicos, partners, and peers even during non-disaster periods. It started conducting regular training sessions, circulating mailers and monthly newsletters and organizing follow-up sessions. It resulted in both the core members and former volunteers to be absorbed in the organization's operations at all times. Also, the institutionalization and continuous engagement with all members of the team allowed greater absorption in DFY's activities. During this phase, the organization also revised its funding model and started focusing on capacity building projects and training as ancillary sources of income apart from voluntary donations and CSR. This phase was also significant as it renewed its focus from organizing around projects to market growth and expansion. Apart from Indian states, it has started functioning in international locations like Nepal and USA. It started forging new long-term partnerships with NGOs and other relief organizations around the world for knowledge exchange. Owing to the realization of permanence, it is also setting up a fully functioning hospital in Bihar, entirely owned and managed by DFY for medical relief, research, training, and capacity building.

\section{Findings and discussion}

Through the previously described observations, we have illustrated the metamorphosis of DFY from a temporary project-based organization into a permanent form and the corresponding changing role of IS during this process. Although scholars like Jacobsson et al. [17] have extended the theory of temporary organizations [21] by putting the transition at the centre of the temporary organization to explore the relationship between temporary and permanent organizations from an intra-organizational perspective but the agency of information-mediated environments in affecting project outcomes is not adequately established. Using this case, we examine the dynamic roles of IS as a core concept in affecting the transformation of a temporary organization to permanence. We continue our discussion of these distinct but intertwined phenomena in the context of disaster relief below: 


\subsection{Transformation from a project-based to a permanent organization}

The case of DFY illustrates the absence of any clear 'peripety' or a sudden moment of change [10] in the form of a single event that led to its transformation. It happened over several intertwined phases characterized by a change in the priorities of the key attributes defining a temporary organization, i.e., time, task, team, and transition [21]. It started with the first instance of the launch of the platelet donation drive in Mumbai. Acquiring and activating a team with the right skills was as important as formalizing the group task and the expected outcomes along with the termination criteria. The lack of resources in this phase ensured that the team was always racing against time and hence had to fulfill its task at the earliest. It was counting backward from the time of its inception. The success of the project depended on measurable outcomes achieved within the proposed time.

"The outcome of the works an organization is doing should be visible.

"Though it is a difficult task for a humanitarian organization to show visible results as many times, it is a subtle enhancement of the lives of people it impacts, but still, the outcome can be made visible by showing numbers. For example, the number of patients treated, the number of emergency workers trained, etc. are a precise quantitative measure of the effectiveness of a disaster management organization"

These measurable outcomes illustrate the transition brought about to the disaster scenario as a result of their efforts. Meeting such milestones reinforced the shared belief of task accomplishment for the team and encouraged them to achieve greater targets later. The team evaluated and exchanged their experience during this project and was then systematically terminated.

The same team was reactivated again during Bihar floods in the following year. This renewal was characterized by reuse of accumulated knowledge from the previous project. The nature of relief efforts offered by DFY remained the same although the disaster characteristics were substantially different. During this phase, the team also identified various issues owing to its newness and smallness. It was not allowed to operate independently and was forced to work with another relief organization led by powerful locals. They initially resisted the idea of collaboration with an unfamiliar team but quickly realized that they could leverage it to fulfill their objectives efficiently. Also, their lack of familiarity with other allied regulatory bodies posed significant challenges to their operations. Mr. Sarbjit Singh Sahota, Emergency Specialist Disaster Risk Reduction, UNICEF India, highlighted these issues:
"Being a young group, the DFY team faced challenges in getting recognition from the government organizations and as a result could not get engaged with them effectively during initial stages. However, they demonstrated commitment and skill over a period and also learned to work with older groups in government organizations which helped them in establishing their place among them."

Hence, identification of the nature of the task and activation of an appropriate team to serve during renewal projects gained higher prominence than describing the expected transition due to the project and the time allocated for the same. This phase was characterized by forging relationships with other organizations participating in relief work. They helped DFY increase its effectiveness manifold and allowed them to provide their services swiftly. It was a rebirth of sorts for DFY when they associated with volunteers from Tata Institute of Social Sciences (TISS) to help the flood victims. The team had learned to mobilize local resources on the ground immediately without backend support in all future project renewals as needed. Since then DFY started using local volunteers and similar bodies to fulfill its rescue efforts swiftly. Dr. Anurag Mishra, Joint Secretary, DFY, recalls

"One practice that reaped great benefit for us was that we used local resources and focused on training the local ASHA workers for response rather than depending solely on doctors from cities."

The next phase was characterized by the diffusion of boundaries between renewal projects. The organizational transformation was focused on developing formal structures inside the firm and forging long-term relationships with other external partners in the disaster relief ecosystem. This formalization was similar to the form of global humanitarian organizations like Red Cross. DFY was growing rapidly in terms of human resources which required a robust organization structure. As discussed earlier, its organizational structure was designed as Core + Flex model with clear demarcation of roles and responsibilities for all members, in all situations. This aided in both accountability and monitoring of the project activities for each instance. It also developed relationships with various partner organizations like ACT India, Mercy Malaysia, and UNICEF. The partnership model at that time was primarily from a funding point of view, where the partners provided fund and logistics and DFY provided the doctors. The organization attempted perpetuity by developing other sustainable and robust revenue streams. Unlike traditional humanitarian organizations which are entirely dependent on donations for their sustenance, DFY started focusing on the generation of funds from 
other avenues like training fees for various disaster preparedness and capacity building programs.

"During a disaster, the people become emotional and donate. However, that source of fund is not predictable, and thus an organization cannot sustain just depending on that."

"We rely on multiple channels of funding which give us stability and sustainability. So our revenue model is very different from the other social entrepreneur's models."

Corporate Social Responsibility (CSR) program of major corporations also helps DFY in exploring partnership opportunities with them. As the organization grew, the partnership model matured and the focus shifted towards collaboration, sharing of expertise, knowledge sharing, and relationship building by complementing each other. As Mr. Sarbjit Singh Sahota asserts

"Our partnership with DFY thrived through mutual benefits. We help DFY in networking - connecting them with right kind of work and also establishing liaison with public institutions and national organizations. We also help training their doctors on the nuances of community work, disaster management and new areas of public health domain. Several manuals, guidance, documents created by UNICEF's global research team are shared with DFY regularly which makes global experience sharing effective."

The role of task and team retained the highest priority during this phase too owing to the compulsions of project renewal and formalization. The combination of various such coordination effects resulted in an overall cognitive change. The firm had already started forging its activities and tasks for its members during non-relief situations too. Its transformation into a permanent organization was clearly discernible over time. Instead of a simple temporary-permanent dichotomy, we cautiously state the existence of both the features in this phase. DFY started focusing on three major segments namely Health Response, Training and Capacity Building and Public Health Awareness Campaigns for both crisis and non-crisis situations. The activities relating to them were executed like individual projects with institutionalized termination, but the perpetuity of the organizational form is a result of systematic overlaps of the temporal bounds of these activities over flexible short-term goals and the fluidic organizational structure supporting such activities. It slowly metamorphosed from a projectbased temporary form to a permanent organization.

\subsection{Role of IS in organizational transformation}

Information systems played a unique and important role in this transformation. They were instrumental in helping develop the communication, coordination and control mechanisms for this transformation.

5.2.1. IS for communication. Disaster struck areas are typically characterized by remoteness due to failure of conventional communication systems. This proves to be a challenge for relief agencies like DFY. It prevents communication with other teams operating in the same region and with the base station. Text-based technologies like messengers and voice-based ones like satellite phones have helped DFY establish the required communication network for access to essential resources as needed. This function of IS is the most primitive. It allows passage of information between two agents using a medium and a common platform. Communication services were critical for the operations of DFY since its launch.

"Communication is very critical for disaster relief operations, especially in the initial stages"

"Since communication channels are disrupted, DFY volunteers on the site use satellite phones for communication with base centers. It allows them to extend their means and resources on ground."

Communication helped link projects with an organizing center. In DFY, it established the linkage between the core team at the center and the doctors at the disaster relief site. Lack of such systems would have led to establishment of this team as an independent project body with little linkage to the organization and further prevented development of permanence in the organizational systems.

5.2.2. IS for coordination. While communication helped develop linkage between the center and the onsite relief teams, coordination between these different teams helped improve their efficiency. While the teams developed for each relief project consisted of a mix of experienced members and new members from the local region, the central team remained the same. The knowledge and experiences of similar past projects helped the central team to coordinate the teams on the ground. However, since the central teams were also transient, IS played a pivotal role in assimilation of this information and their transference between such teams.

"Our teams used messengers like WhatsApp to coordinate with the central team. They helped them with information and resources which were not otherwise accessible to them. Without such coordination, these different teams would be directionless and hence not as effective."

DFY realized the importance of such coordination between the teams after success in its initial projects. The core team members realized that temporary project teams sent to different relief projects often faced similar problems. Hence, a shared project group was 
created for each different relief project in WhatsApp, and new team members were given access to it. It allowed them to access knowledge of similar situations in the past and coordinate with different team members at once. They were no longer needed to pass on the same information to different team members with varying roles but within the same project group. It helped improve the efficiency and effectiveness of the relief projects and simultaneously led to the development of a relatively formal coordination network. This channel was one of the early organizational structures which helped in maturing the temporary form towards permanence.

5.2.3. IS for control. The role of IS had matured along with the development of the organization. Earlier, the WhatsApp groups were used to pass information to the teams, but slowly the core members started to participate actively in the group to monitor the progress of the teams on relief site. Further, apart from these groups, new groups were created for projects after the primary relief operations were over.

"Whenever a new team was assigned to a new relief project, all the team members were made added to a WhatsApp group which also consisted of core members like me and some other senior doctors and coordinators of local DFY centers. Slowly, this platform was used to share information and to monitor the effectiveness of the teams. They used to send photographs etc. to share details of ongoing work and issues if any."

Such mechanisms enabled the existence of these groups, which had become proxy for projects, beyond the life of the associated projects. Hence, these groups became instrumental in extension of the life of primary project groups and to the transformation of the organization from temporariness towards permanence.

\section{Implications of the study}

Information systems play varied roles at different junctures of the organizational development. Decision makers in such organizations can use the learnings from this study to plan transformation to a continued existence. They can optimally utilize IS in varied forms at different junctures of its growth for various roles. While this case illuminates the changing roles of IS from communication to coordination to control, other organizations can use them suitably aligned to their organizational objectives and trajectories.

While the outcomes of this study have significant implications for practicing managers, scholarship in the project management domain shall significantly improve with this study. While there have been studies which explored the temporariness of project-based organizations and other permanent organizations, this study shall help connect those two diverse organizational forms. Further, the role of IS in such transformation has rarely been discussed. Modern organizations existing in multiple sites and coordinating among various networked structures use IS extensively, but their role in affecting the core characteristic of an organization is important and needs to be explored further. Future scholarship shall examine the efficacy of IS and their role in such transformation across other domains. Simultaneously, their effectiveness in such transformation needs to be empirically investigated too. Such inquiries are critical for establishing this role of IS.

\section{Conclusion}

There has been some research on both temporary and permanent organizational forms, but there has been little research on the different roles of IS and their impact on transformation of organizational forms. Further, the context of disaster management has not been explored in depth. Although this study consists of a discussion of a single case, it presents opportunities for research in multiple other topics like temporary organizations, their transformation to permanence and the role of IS in it. This study helps develop a vocabulary for future research on the theme of transformation to perpetuity for such organizations. The proposed model based on phases of evolution of the organizational form helps examine the transformational process dynamically. The changing engagements of information tools along with project experience are also unique to this study. The process of changing roles of IS needs further engagement to establish a robust understanding of the process of transformation for temporary organizations into project-based permanent organizations.

\section{References}

[1] Argote, L. Input Uncertainty and Organizational Coordination in Hospital Emergency Units. Administrative Science Quarterly 27, 3 (1982), 420-434.

[2] Bechky, B. a. Gaffers, Gofers, and Grips: Role-Based Coordination in Temporary Organizations. Organization Science 17, 1 (2006), 3-21.

[3] Bigley, G.A. and Roberts, K.H. The incident command system: High-reliability organizing for complex and volatile task environments. Academy of Management Journal 44, 6 (2001), 1281-1299.

[4] de Bruijn, H. One fight, one team: The 9/11 commission report on intelligence, fragmentation and information. Public Administration 84, 2 (2006), 267-287. 
[5] Cacciatori, E. Memory objects in project environments: Storing, retrieving and adapting learning in project-based firms. Research Policy 37, 9 (2008), 1591-1601.

[6] Comfort, L.K. and Kapucu, N. Inter-organizational coordination in extreme events: The World Trade Center attacks, September 11, 2001. Natural Hazards 39, 2 (2006), 309-327.

[7] Cova, B. and Salle, R. Six key points to merge project marketing into project management. International Journal of Project Management 23, 5 SPEC. ISS. (2005), 354-359.

[8] Dini, A.A., Wahid, F., and Sæbo, Ø. Affordances and Constraints of Social Media Use in eParticipation: Perspectives from Indonesian Politicians. 20th Pacific Asia Conference on Information Systems (PACIS 2016), (2016), $1-14$.

[9] Eisenhardt, K.M. Building Theories from Case Study Research. Academy of Management Review 14, 4 (1989), $532-550$.

[10] Engwall, M. No project is an island: Linking projects to history and context. Research Policy 32, 2003, 789-808.

[11] Faulkner, R.R. and Anderson, A.B. Short-Term Projects and Emergent Careers: Evidence from Hollywood. American Journal of Sociology 92, 4 (1987), 879.

[12] Galbraith, J. Organization design: An information processing view. Interfaces 4, (1974), 28-36.

[13] George, A.L. and Bennett, A. Case Studies and Theory Development in the Social Sciences. MIT Press, (2005), 432.

[14] Goodman, R.A. and Goodman, L.P. Some Management Issues in Temporary Systems: A Study of Professional Development and Manpower-The Theater Case. Administrative Science Quarterly 21, 3 (1976), 494-501.

[15] Hobday, M. The project-based organisation: an ideal form for managing complex products and systems? Research Policy 29, 7-8 (2000), 871-893.

[16] Ibert, O. Projects and firms as discordant complements: Organisational learning in the Munich software ecology. Research Policy 33, 10 (2004), 1529-1546.

[17] Jacobsson, M., Burström, T., and Wilson, T.L. The role of transition in temporary organizations: linking the temporary to the permanent. International Journal of Managing Projects in Business 6, 3 (2013), 576-586.

[18] Jick, T. Mixing Qualitative and Quantitative Methods: Triangulation in Action. Administrative Science Quarterly 24, 4 (1979), 602-611.

[19] Jordão, R.V.D., Souza, A.A., and Avelar, E.A. Organizational culture and post-acquisition changes in management control systems: An analysis of a successful Brazilian case. Journal of Business Research 67, 4 (2014), $542-549$.
[20] Lee, J. and Bui, T. A template-based methodology for disaster management information systems. Proceedings of the 33rd Annual Hawaii International Conference on System Sciences 0, c (2000), 1-7.

[21] Lundin, R.A. and Söderholm, A. A theory of the temporary organization. Scandinavian Journal of Management 11, 4 (1995), 437-455.

[22] Maaninen-Olsson, E. and Müllern, T. A contextual understanding of projects-The importance of space and time. Scandinavian Journal of Management 25, 3 (2009), 327-339.

[23] Martyna Janowicz-Panjaitan, Bakker, R.M., and Kenis, P. Research on temporary organizations: The state of the art and distinct approaches toward temporariness. In P. Kenis, M. Janowicz-Panjaitan and B. Cambré, eds., Temporary Organizations: Prevalence, Logic and Effectiveness. Edward Elgar Publishing, 2009, 56-85.

[24] Middleton, C., Scheepers, R., and Tuunainen, V.K. When mobile is the norm: researching mobile information systems and mobility as post-adoption phenomena. European Journal of Information Systems 23, 5 (2014), 503-512.

[25] Minayo, M.C. de S. Pesquisa Social. Teoria, Método e criatividade. 1994.

[26] Müller-Seitz, G. and Sydow, J. Terminating institutionalized termination: Why Sematech became more than a temporary system. In Advances in Strategic Management 28: Project-Based Organizing and Strategic Management. 2011, 147-186.

[27] Packendorff, J. Inquiring into the temporary organization: New directions for project management research. Scandinavian Journal of Management 11, 4 (1995), 319-333.

[28] Tufekci, S. and Wallace, W. a. The Emerging Area Of Emergency Management And Engineering. IEEE Transactions on Engineering Management 45, 2 (1998), 103-105.

[29] Turner, J.R. and Müller, R. On the nature of the project as a temporary organization. International Journal of Project Management 21, 1 (2003), 1-8.

[30] Yates, D. and Paquette, S. Emergency knowledge management and social media technologies: A case study of the 2010 Haitian earthquake. International Journal of Information Management 31, 1 (2011), 6-13.

[31] Yin, R. Case study research: Design and methods. Sage Publishing, Beverly Hills, 1984.

[32] Zheng, L., Shen, C., Tang, L., Li, T., Luis, S., and Chen, S.-C. Applying data mining techniques to address disaster information management challenges on mobile devices. Proceedings of the 17th ACM SIGKDD international conference on Knowledge discovery and data mining - KDD '11, (2011), 283. 